\section{JOURNAL OF MODERN MANUFACTURING SYSTEMS AND TECHNOLOGY}

\title{
Study on the effects of nozzle distance to surface roughness of workpiece under minimum quantity lubricant (MQL) milling
}

\section{process}

\author{
Firdaus Shazriq Mohd Fadzil ${ }^{1+}$, Nur Izzati Khoirunnisa Ismail ${ }^{1+}$, Nurrina Rosli $^{1 *}$
}

\begin{abstract}
*Correspondence
nurrinarosli@ump.edu.my

+This author contributes equally to this work

${ }^{1}$ Faculty of Manufacturing Engineering, Universiti Malaysia Pahang, 26600, Pekan, Pahang, Malaysia
\end{abstract}

\begin{abstract}
Application of cutting oil during machining process has been the most important contributor for the development of manufacturing sectors. There are many types of machining technologies developed with cutting oil supply system such as minimum quantity lubricant (MQL). With very little supply of lubricant, it can lengthen the cutting tool life and surface roughness of workpiece. Although the low consumption of lubricant is favourable, study on the performance of MQL machining process must be strengthened enough since the high penetration ability of very little amount of lubricant oil is important. Many researches have been carried out since decades ago to study the MQL performance. However, investigation on the effects on nozzle position have not been treated in much detail. Here, this paper is aimed to investigate the effects of nozzle distance to surface roughness of workpiece under MQL milling process. Experimental approach was done mainly under different nozzle distance varied in horizontal direction from the cutting tool. Other than that, the effects of feed rate and spindle speed to the surface roughness were also investigated. As a result, surface roughness increases with increasing feed rate. At lower operation of spindle speed, surface roughness rapidly increases with increasing feed rate compared to higher operated spindle speed. Operation under high feed rate leads to a decreasing surface roughness with increasing spindle speed. Milling under high feed rate for all conditions of nozzle distance can still give a great surface roughness for a workpiece, only if the spindle speed is increased. Surface roughness decreases with increasing distance of nozzle to workpiece in horizontal direction.
\end{abstract}

Minimum quantity

lubrication

Nozzle distance

Surface roughness

Milling process

Articles Info:

Received 25 June 2018

24 Jul 2018

Available Online 13 Sept

\section{INTRODUCTION}

Application of cutting oil during machining process has been the most important contributor for the development of manufacturing sectors due to their capabilities in fulfilling compulsory requirement of cooling and lubricating process in various metal working operations [1]. Applying the cutting oils can reduce friction generated between cutting tool and workpiece as well as high temperature production during a process by dissipating the initiated heat. To highlight, letting the cutting oils to flow over the tool 
and workpiece [2] can avoid destruction of workpiece material and cutting tool due to the thermal damage during the cutting process. Therefore, providing a great cooling and lubricating effects can improve manufacturing operations and thus increase productivity.

There are many types of machining technologies developed with cutting oil supply system. Flood cooling machining is commonly used when there are large temperature gradient and sparks occurrence. However, it is not favourable compared to others since excessive coolant amount and thus extensive cleaning process are needed. High pressure cooling machining is among the most effective ones as it utilizes coolant jets with accurate alignment and extremely high pressure. Despite widely used in machining tough materials in aerospace industry [2], cryogenic cooling machining is characterized as an ecological machining technology since it applies liquid nitrogen or frozen carbon dioxide as the coolant. Furthermore, minimum quantity cooling lubrication (MQCL) machining is said to be more effective and productive as it can be used in universal condition. It is also nature-friendly and applicable to reduce the drawbacks of the high temperature machining operation [3].

MQCL can be classified into minimum quantity lubricant (MQL) and minimum quantity cooling (MQC). MQL used compressed air and oils as its lubricant whereas MQC employs emulsions rather than oils. However, MQC does not widely used in industry as its emulsion produce low lubricating effect compared to MQL [2] that brings in numerous advantages to the manufacturing sectors. With very little supply of lubricant, it is still capable in lengthening the cutting tool life and refining the machining performance in the aspects of the workpiece surface roughness, cutting force needed as well as its process capability. Furthermore, it also presents minimal environmental impact and naturally eliminate the health issues of the workers [4] because total amount of liquid being consumed is extremely small. While typical wet machining needs lubricant in 12,000 litre/hour, MQL only requires 0.05 litre/hour or lesser amount [4]. Thus, the manufacturing cost is extremely low [5].

Although the low consumption of lubricant is favourable, study on the performance of MQL machining process must be strengthened enough since the high penetration ability of very little amount of lubricant oil is important. Many researches have been carried out since decades ago to study the MQL performance [6-7]. Sasahara et al. [8] proved that tool wear can still be reduced with even very small amount of lubricant in MQL machining which resulted by the reduction of cutting temperature. Nizamuddin et al. [9] stated that the using karanja oil as cutting fluid gives a better machining performance due to its higher flash point and molecular weight which can reduce the vaporization ability. Thus, greater density with a high lubricated oil film can aid varying cutting parameters. Talib and Rahim [10] relates the viscosity effects of modified jatropha oils to its ability in resisting friction and wear between tool and chips by separating the sliding surfaces between the two contact surfaces. Park et al. [11] performed a study to investigate the influence of nozzle distance to workpiece and nozzle discharge pressure on the lubricant droplets size and distribution. They found that longer nozzle distance gave a lesser amount of droplets but higher nozzle pressure can provide more droplets with smaller size. Duchosal et al. [12] reported that outlet diameter of oil mist generator under milling process has no effect on the flow velocity of the fluid. However, higher oil viscosity provides smaller size of oil particles as collision within particles and particles to channel wall can be avoided with absence of supplementary pressurized air.

Further study on the oil droplets size changes was done by Cabanettes et al. [13] where they found that the droplet size is greatly changed prior to the oil mist distribution to cutting tool. It was noted that droplets coagulation upon collisions, droplets breakup, oil film formation and breakup on inner pipe wall occurred during delivery through the pipeline from the mist generator to the cutting tool. Brinksmeier et al. [14] highlighted that study of metalworking fluid itself is significant to evaluate their effects in manufacturing process like other parameter. As the characteristics of cutting fluids is noticeable important for the manufacturing process performance, investigation on the fluids behaviour is hardly to neglect. As stated by Duchosal et al. [15], study on the effects of nozzle placement is hardly to ignore as the lubricant oil sprayed out from the nozzle may possibly off to the cutting zone during machining process. To date, such investigation has not been treated in much detail.

Here, this paper is aimed to investigate the effects of nozzle distance to surface roughness of workpiece under MQL milling process. Experimental approach was done mainly under different nozzle distance varied in horizontal direction from the cutting tool. Other than that, the effects of feed rate and spindle speed to the surface roughness were also investigated.

\section{EXPERIMENTAL SETUP AND PROCEDURE}

Minimum Quantity Lubrication (MQL) machining process was generated using lubricant generator made by Unist's Coolubricator ${ }^{\mathrm{TM}}$ attached to a CNC Makino milling machine as shown in Fig. (1). The oil lubricant used in the experimental was Coolube ${ }^{\circledR} 2210 \mathrm{EP}$ while the workpiece material used was 
aluminium Al6061 in dimension of $100 \mathrm{~mm} \times 100 \mathrm{~mm} \times 45 \mathrm{~mm}$. The image of machined workpiece is shown in Fig. (2). The properties of both oil lubricant and workpiece material is shown in Table 1. The surface roughness of machined workpiece was measured using Mitutoyo surface roughness tester. The nozzle was fixed to $45^{\circ}$ from the cutting tool and perpendicular to the feed direction. The experiment was mainly conducted under different distance of nozzle, $d$ which was varied in horizontal direction from the cutting tool as illustrated in Fig. (3). The milling process was done multiple times to get an average value of the surface roughness, $R_{a}$. The influence of feed rate, $V_{f}$ and spindle speed, $n$ to the surface roughness were also investigated. Details of the experimental condition and parameters is shown in Table 2.

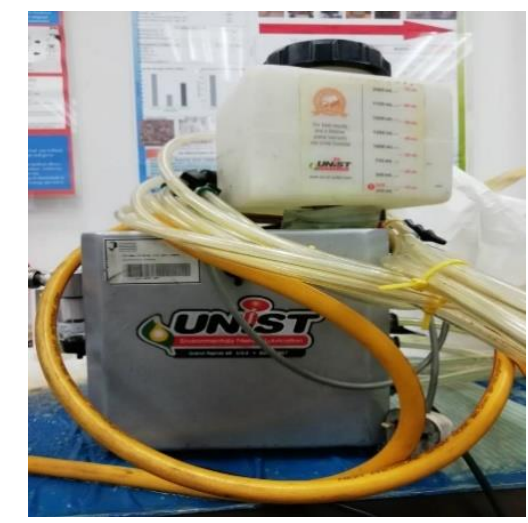

Figure 1: Unist's CoolubricatorTM for MQL generator

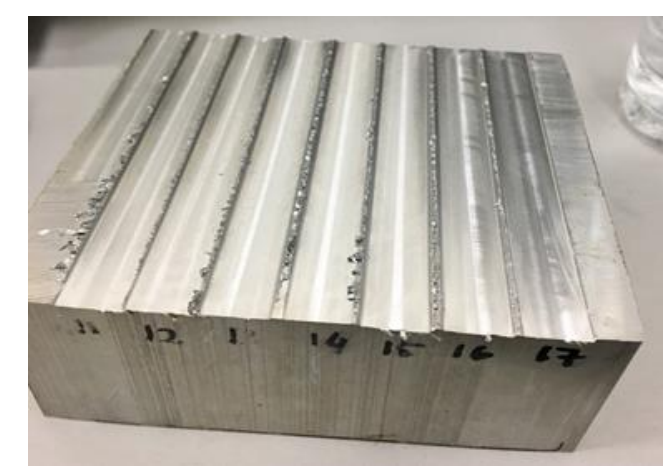

Figure 2: Image of machined workpiece

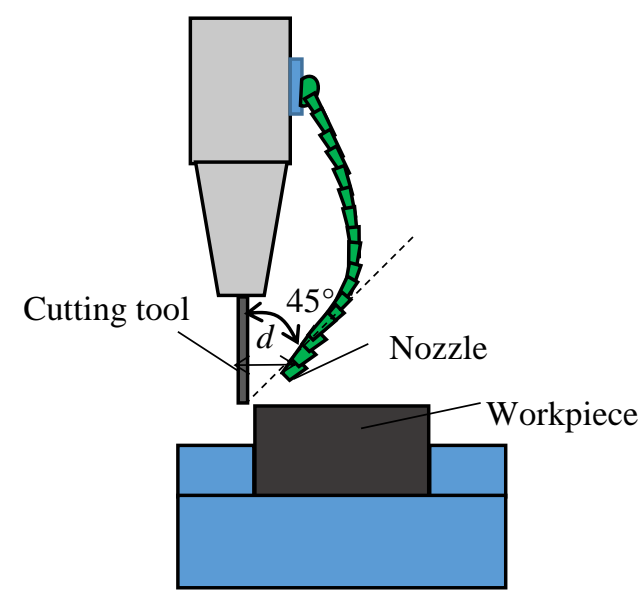

Figure 3: Illustration of nozzle position towards cutting zone

Table 2: Experimental condition and parameters

\begin{tabular}{lc}
\hline & Experimental condition \\
\hline Cutting tool & Coated carbide End mill \\
Depth of cut & $0.3 \mathrm{~mm}$ \\
Air pressure & $0.035 \mathrm{MPa}$ \\
Lubricant flow rate & $0.15 \mathrm{ml} / \mathrm{min}$ \\
Nozzle position & $45^{\circ}$ from cutting tool, perpendicular \\
& to feed direction \\
\hline \multicolumn{2}{c}{ Experimental parameters } \\
\hline Nozzle distance, $d$ & $5,20,35 \mathrm{~mm}$ in horizontal direction \\
Feed rate, $V_{f}$ & $230,270,310 \mathrm{~mm} / \mathrm{min}$ \\
Spindle speed, $n$ & $1200,1400,1600 \mathrm{rpm}$ \\
\hline
\end{tabular}




\section{RESULTS AND DISCUSSIONS}

Results of surface roughness of machined workpiece under nozzle distance of $5 \mathrm{~mm}, 20 \mathrm{~mm}$ and $35 \mathrm{~mm}$ are shown in Fig. (4), Fig. (5) and Fig. (6), respectively. Roughly, the surface roughness under all conditions of nozzle distance was found to increase with increasing feed rate. This trend is expected since the similar reports has been published by Azuddin and Abdullah [16] that stated the dynamic forces on the tool as the reason of surface roughness increases when increasing the feed rate. Moreover, a closer look to all figures further shows a same trend where surface roughness was found to rapidly increase with increasing feed rate during the lowest spindle speed i.e.1200 $\mathrm{min}^{-1}$ compared to higher operated spindle speed. This indicates that milling under lower spindle speed significantly gives a high surface roughness of workpiece with increasing feed rate. This finding is also strengthened by the report of Abdullah et. al [17] that highlighted the feed rate as the most influential parameter in giving the value of surface roughness of a workpiece.

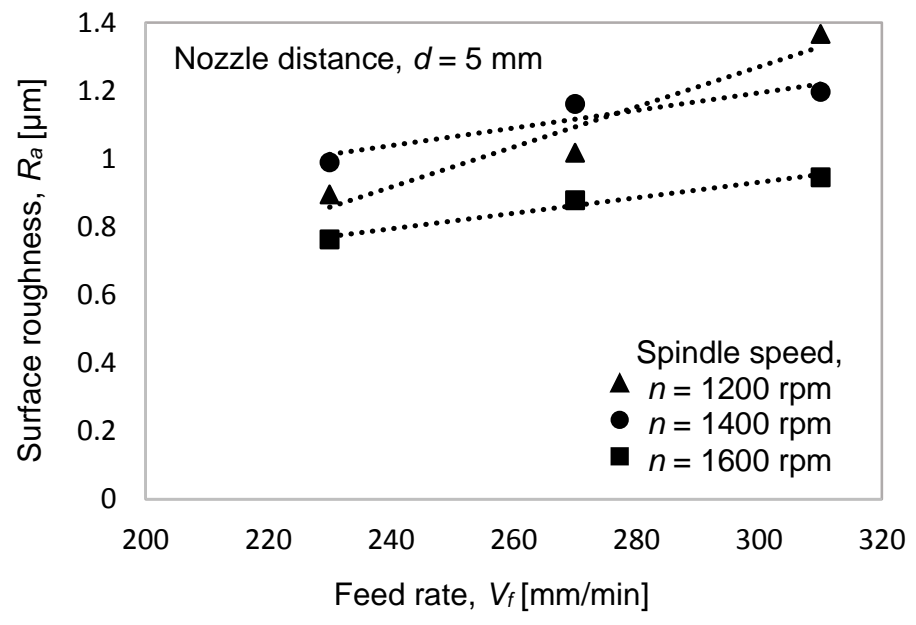

Figure 4: Results of surface roughness of workpiece under nozzle distance, $d=5 \mathrm{~mm}$

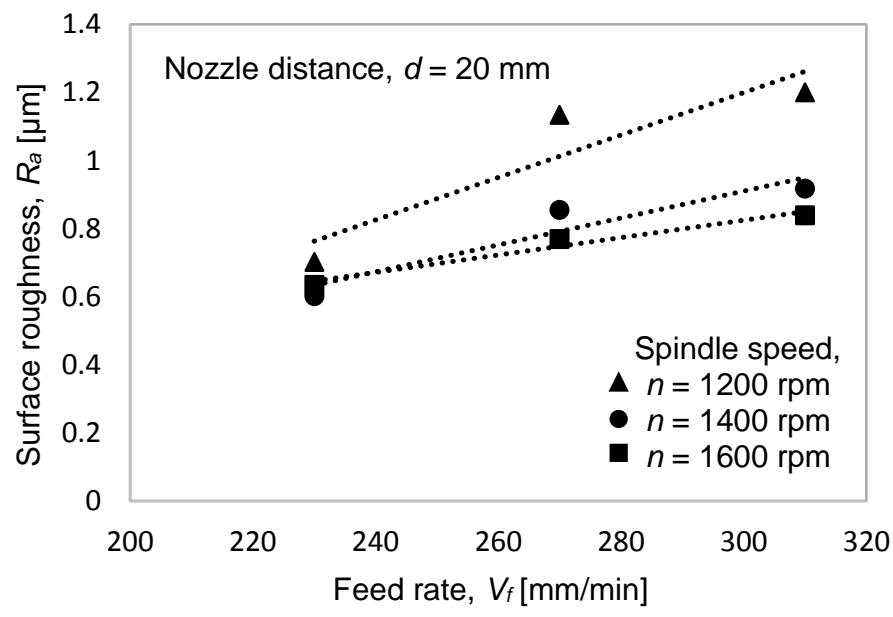

Figure 5: Results of surface roughness of workpiece under nozzle distance, $d=20 \mathrm{~mm}$

On the other hand, it was found that operation under low feed rate to achieve low surface roughness of workpiece is not necessarily needed at some point. Observation to all conditions of nozzle distance discovers a decreasing surface roughness by increasing spindle speed under feed rate as high as $310 \mathrm{~mm} / \mathrm{min}$. This suggests that milling under high feed rate can still give much lower surface roughness, only if the spindle speed is increased Although this finding is contradict to what has been reported by Aoyama [18], the centrifugal force caused by the high spindle speed do not influence the cutting oil to fly off the cutting zone since the air pressure in the present project was set as much lower. Instead, more 
volume of oil can penetrate the cutting zone since the spindle rotation can counter back the vibration caused by feeding the workpiece.

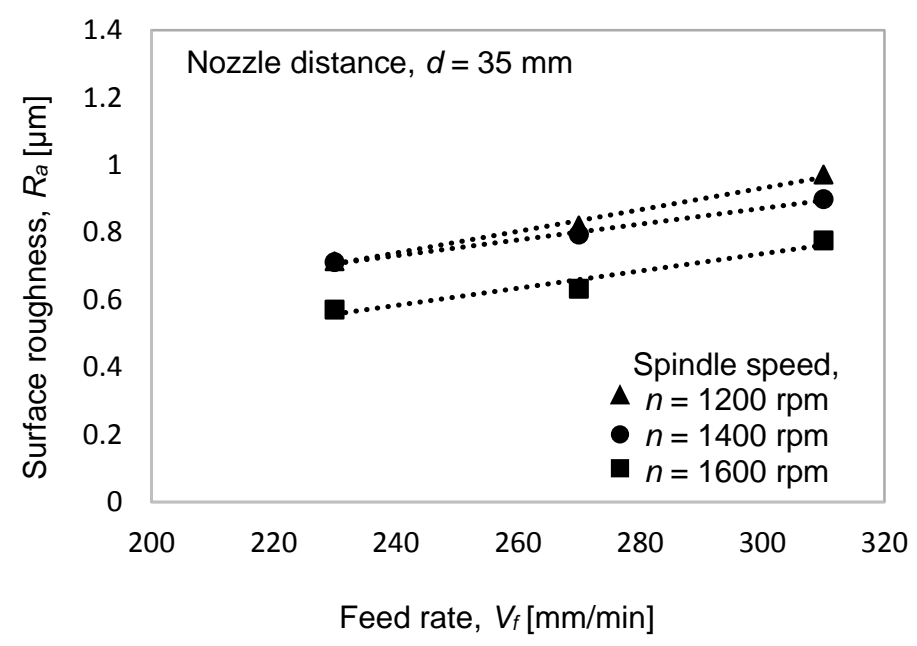

Figure 6: Results of surface roughness of workpiece under nozzle distance, $d=35 \mathrm{~mm}$

Moreover, the surface roughness for nozzle distance of $5 \mathrm{~mm}, 20 \mathrm{~mm}$, and $35 \mathrm{~mm}$ were found to range within $0.7 \mu \mathrm{m}$ to $1.3 \mu \mathrm{m}, 0.6 \mu \mathrm{m}$ to $1.2 \mu \mathrm{m}$ and $0.5 \mu \mathrm{m}$ to $1 \mu \mathrm{m}$, respectively. Although a project by Park et a.[11] found that increasing nozzle distance in vertical direction from workpiece leads to a lower surface roughness. Meaning that, the surface roughness in the present project was found to decrease by increasing the nozzle distance in horizontal direction from the cutting tool. Nevertheless, the nozzle was also positioned in perpendicular to the feeding direction which is considered a good alternative to avoid removed chip and lubricant jet interference as reported by Lacalle et al. [19].

\section{CONCLUSIONS}

This paper is aimed to investigate the effects of nozzle distance to surface roughness of workpiece under MQL milling process. Experimental approach was done mainly under different nozzle distance varied in horizontal direction from the cutting tool. Other than that, the effects of feed rate and spindle speed to the surface roughness were also investigated. Several points have been concluded as follow:

1. Roughly, surface roughness increases with increasing feed rate. At lower operation of spindle speed, surface roughness rapidly increases with increasing feed rate compared to higher operated spindle speed.

2. Operation under high feed rate leads to a decreasing surface roughness with increasing spindle speed. Meaning that, milling under high feed rate for all conditions of nozzle distance can still give a great surface roughness for a workpiece, only if the spindle speed is increased.

3. Surface roughness decreases with increasing distance of nozzle in horizontal direction from the cutting tool.

\section{ACKNOWLEDGEMENT}

Authors wish to acknowledge the Research \& Innovation Department of University Malaysia Pahang for the financial support given to complete this project (Grant number: RDU1703158).

\section{REFERENCES}

[1] G. Ríos, C. Pazos, and J. Coca, "Destabilization of cutting oil emulsions using inorganic salts as coagulants," Colloids Surfaces A Physicochem. Eng. Asp., vol. 138, no. 2-3, pp. 383-389, 1998.

[2] S. Anton, S. Andreas, and B. Friedrich, "Heat dissipation in turning operations by means of internal cooling," Procedia Eng., vol. 100, no. January, pp. 1116-1123, 2015. 
[3] C. Bruni, A. Forcellese, F. Gabrielli, and M. Simoncini, "Effect of the Iubrication-cooling technique, insert technology and machine bed material on the workpart surface finish and tool wear in finish turning of AISI 420B," Int. J. Mach. Tools Manuf., vol. 46, no. 12-13, pp. 1547-1554, 2006.

[4] S. Madhukar, A. Shravan, P. Vidyanand, and G. S. Reddy, "A Critical review on Minimum Quantity Lubrication (MQL) Coolant System for Machining Operations,” Int. J. Curr. Eng. Int. J. Curr. Eng. Technol., vol. 6, no. 5, pp. 1745-1751, 2016.

[5] B. L. Tai, D. A. Stephenson, R. J. Furness, and A. J. Shih, "Minimum quantity lubrication (MQL) in automotive powertrain machining," Procedia CIRP, vol. 14, pp. 523-528, 2014.

[6] H. Hegab, U. Umer, M. Soliman, and H. A. Kishawy, "Effects of nano-cutting fluids on tool performance and chip morphology during machining Inconel 718," Int. J. Adv. Manuf. Technol., 2018.

[7] N. Talib and E. A. Rahim, "Performance of modified jatropha oil in combination with hexagonal boron nitride particles as a biobased lubricant for green machining," Tribol. Int., vol. 118, no. September 2017, pp. 89-104, 2018.

[8] H. Sasahara, K. Satake, W. Takahashi, M. Goto, and H. Yamamoto, " The effect of oil mist supply on cutting point temperature and tool wear in driven rotary cutting,” Precis. Eng., vol. 48, pp. 158163, 2017.

[9] M. Nizamuddin, S. M. Agrawal, and N. Patil, "The Effect of Karanja based Soluble Cutting Fluid on Chips Formation in Orthogonal Cutting Process of AISI 1045 Steel," Procedia Manuf., vol. 20, pp. 12-17, 2018.

[10] N. Talib and E. A. Rahim, "Performance of modified jatropha oil in combination with hexagonal boron nitride particles as a biobased lubricant for green machining," Tribol. Int., vol. 118, no. September 2017, pp. 89-104, 2018.

[11] K. H. Park, J. Olortegui-Yume, M. C. Yoon, and P. Kwon, “A study on droplets and their distribution for minimum quantity lubrication (MQL),” Int. J. Mach. Tools Manuf., vol. 50, no. 9, pp. 824-833, 2010.

[12] A. Duchosal, R. Leroy, L. Vecellio, C. Louste, and N. Ranganathan, “An experimental investigation on oil mist characterization used in MQL milling process,” Int. J. Adv. Manuf. Technol., vol. 66, no. 5-8, pp. 1003-1014, 2013.

[13] F. Cabanettes, P. Faverjon, A. Sova, F. Dumont, and J. Rech, "MQL machining: from mist generation to tribological behavior of different oils,” Int. J. Adv. Manuf. Technol., vol. 90, no. 1-4, pp. 11191130, 2017.

[14] E. Brinksmeier, D. Meyer, A. G. Huesmann-Cordes, and C. Herrmann, "Metalworking fluids Mechanisms and performance,” CIRP Ann. - Manuf. Technol., vol. 64, no. 2, pp. 605-628, 2015.

[15] A. Duchosal, R. Leroy, L. Vecellio, C. Louste, and N. Ranganathan, "An experimental investigation on oil mist characterization used in MQL milling process," Int. J. Adv. Manuf. Technol., vol. 66, no. 5-8, pp. 1003-1014, 2013.

[16] M. Azuddin and W. Abdullah, "A Study on surface roughness and burr formation of Al6061 with different spindle speed and federate for small end milling cutter," Int. J. Integr. Eng., vol. 1, no. 1, 2011.

[17] A. B. Abdullah, L. Y. Chia, and Z. Samad, "The Effect of Feed Rate and Cutting Speed to Surface Roughness," Asian J. Sci. Res., vol. 1, no. 1, pp. 12-21, 2008.

[18] T. Aoyama, "Development of a mixture supply system for machining with minimal quantity Iubrication,” CIRP Ann. - Manuf. Technol., vol. 51, no. 1, pp. 289-292, 2002.

[19] L. N. López De Lacalle, C. Angulo, A. Lamikiz, and J. A. Sánchez, "Experimental and numerical investigation of the effect of spray cutting fluids in high speed milling," J. Mater. Process. Technol., vol. 172, no. 1, pp. 11-15, 2006 